\title{
Time to evaluate biomarkers for use in directing treatment strategies in ARDS patients
}

\author{
Benjamin Coiffard and Laurent Papazian*
}

(c) 2018 Springer-Verlag GmbH Germany, part of Springer Nature and ESICM

Biomarkers have been extensively studied in acute respiratory distress syndrome (ARDS), but none of them are currently used in clinical practice $[1,2]$.

Some biomarkers are considered to be more specific regarding lung injury. The receptor for advanced glycation end products (RAGE) is one of them, being highly expressed in the lung epithelium. Moreover, plasma levels of soluble RAGE (sRAGE) reflect the extent of alveolar type I cell injury [3]. In acid-injured mice, it has been found that the rate of alveolar fluid clearance is inversely correlated with sRAGE levels in plasma and bronchoalveolar fluid [3]. It has also been reported that plasma sRAGE was also correlated with alveolar fluid clearance in 30 patients with ARDS [3]. In a large population of ARDS patients (patients from the ARMA study [4]), Calfee et al. [5] reported that higher baseline levels of plasma sRAGE were associated with a lower arterial oxygen tension/fraction of inspired oxygen ratio, lower compliance, and higher clinical and radiographic lung injury scores. Interestingly, higher baseline plasma sRAGE levels were associated with higher pre-randomisation tidal volume and plateau pressure [5]. Baseline sRAGE levels were also significantly higher in subjects who died compared with those who survived, but the most interesting observation was that the extent of decline in plasma sRAGE levels over the first 3 days was $15 \%$ greater in the $6 \mathrm{ml} / \mathrm{kg}$ group compared with the $12 \mathrm{ml} / \mathrm{kg}$ group [5]. This latter result [5] suggests that sRAGE is a reliable marker to evaluate the modulation of the magnitude of epithelial injury linked to the ventilation strategy.

\footnotetext{
*Correspondence: laurent.papazian@ap-hm.fr

Centre d'Etudes et de Recherches sur les Services de Santé et qualité de vie EA3279, APHM, Hôpital Nord, Médecine Intensive-Réanimation, AixMarseille Université, 13015 Marseille, France
}

Other biomarkers are of interest and can be associated with sRAGE, such as angiopoietin-2, which is a marker of endothelial injury $[6,7]$. The combination of biomarkers is used to differentiate the patient presenting with a direct lung injury from those with an indirect mechanism of ARDS [8]. Indeed, based on the assessment of two biomarkers, it was reported that ARDS resulting from direct lung injury is characterised by a molecular phenotype consistent with more severe lung epithelial injury and less severe endothelial injury [8]. This is a very interesting approach, and it suggests that the determination of biomarkers is not limited to diagnosis but could also be used to adjust the therapeutic strategy. There is also an overlap between the mechanisms of lung injury (direct vs. indirect), and the anatomical aspects as explored by CT scan. Indirect lung injury is usually characterised by a homogeneous distribution of radiological infiltrates (diffuse or nonfocal forms), whereas patients with direct lung injury present a heterogeneous distribution of lung infiltrates with more focalised infiltrates. In this way, sRAGE is able to differentiate focal from diffuse ARDS (CT scan aspects), as shown in a series of 119 patients [9]. It was reported that plasma levels of sRAGE were significantly higher in nonfocal ARDS compared with focal ARDS [9]. Interventions such as recruitment manoeuvres have been shown to induce early variations of sRAGE [10]. This is a very attractive characteristic to direct ventilator strategy. Even for patients without previous lung injury who underwent major abdominal surgery, a lung-protective ventilation strategy induced a decrease in plasma sRAGE compared with patients with a non-protective ventilation strategy [11].

Numerous biomarkers [12] have been shown to be associated with outcomes in ARDS patients. Type III procollagen is one of them. It is associated with both

\section{Springer}


the outcome and the presence of lung fibroproliferation [13]. This biomarker will be tested in the near future for directing the prescription of corticosteroids in prolonged ARDS.

A more recent approach is to combine multiple biological and non-biological parameters in order to define more homogeneous groups of ARDS patients (subphenotypes) with different physiopathological mechanisms of lung injury, different outcomes and, finally, differential responses to treatment. This is the era of precision and personalised medicine applied to intensive care medicine. In a very important contribution [14], Calfee et al. identified two subphenotypes by analysing information from patients included in the ARMA and in the ALVEOLI trials. One subphenotype was labelled hyperinflammatory, as it was characterised by higher plasma concentrations of inflammatory biomarkers, a higher prevalence of vasopressor use, lower serum bicarbonate concentrations, and a higher prevalence of sepsis compared with the noninflammatory subphenotype [14]. Patients from this hyperinflammatory subphenotype had higher mortality and fewer ventilator-free days and fewer days free of organ failure, than did those in the noninflammatory subphenotypes [14]. However, one major result was that in the ALVEOLI cohort exploring the beneficial effect of high PEEP levels, the effects of the ventilation strategy on mortality and other outcomes differed according to subphenotype [14]. Indeed, the high PEEP strategy induced beneficial effects regarding all the assessed outcomes, but only in the hyperinflammatory subphenotype (worse effects being observed in the other subphenotype) [14]. By identifying a hyperinflammatory subphenotype using three biomarkers (interleukin-8, bicarbonate, and tumour necrosis factor receptor-1), a similar distinct effect was observed regarding the effect of fluid strategy in ARDS patients [15]. Indeed, the restrictive fluid strategy was beneficial only in patients from the hyperinflammatory subphenotype.

In an article recently published in Intensive Care Medicine, Jabaudon et al. conducted a meta-analysis of individual data from 746 patients across eight studies in whom a blood determination of plasma sRAGE had been made [16]. They reported that non-survivors at day 90 had higher baseline levels of sRAGE compared with survivors. Finally, baseline sRAGE was independently associated with 90-day mortality. These results support the assumption that sRAGE is a reliable marker of the extent of alveolar epithelial injury. Unfortunately, there were no repeated measurements that would permit an assessment of resolution or the unfavourable evolution of lung injury. Future investigations are needed to determine if sRAGE is able to direct ventilation strategy or other treatments aiming to reduce the extent of lung injury.
More generally, recent advances in the development of new biological testing technologies that make the results available in a few minutes or hours will amplify the use of biomarkers to direct therapeutic strategies.

\section{Compliance with ethical standards}

Conflicts of interest

All authors declare that they have no conflict of interest.

Received: 8 July 2018 Accepted: 13 July 2018

Published online: 23 August 2018

References

1. Papazian L, Calfee CS, Chiumello D, Luyt CE, Meyer NJ, Sekiguchi H, Matthay MA, Meduri GU (2016) Diagnostic workup for ARDS patients. Intensive Care Med 42:674-685

2. Ware LB, Calfee CS (2016) Biomarkers of ARDS: what's new? Intensive Care Med 42:797-799

3. Jabaudon M, Blondonnet R, Roszyk L, Bouvier D, Audard J, Clairefond G, Fournier M, Marceau G, Dechelotte P, Pereira B, Sapin V, Constantin JM (2015) Soluble receptor for advanced glycation end-products predicts impaired alveolar fluid clearance in acute respiratory distress syndrome. Am J Respir Crit Care Med 192:191-199

4. Acute Respiratory Distress Syndrome N, Brower RG, Matthay MA, Morris A, Schoenfeld D, Thompson BT, Wheeler A (2000) Ventilation with lower tidal volumes as compared with traditional tidal volumes for acute lung injury and the acute respiratory distress syndrome. N Engl J Med 342:1301-1308

5. Calfee CS, Ware LB, Eisner MD, Parsons PE, Thompson BT, Wickersham N, Matthay MA, Network NA (2008) Plasma receptor for advanced glycation end products and clinical outcomes in acute lung injury. Thorax 63:1083-1089

6. Yehya N, Thomas NJ, Meyer NJ, Christie JD, Berg RA, Margulies SS (2016) Circulating markers of endothelial and alveolar epithelial dysfunction are associated with mortality in pediatric acute respiratory distress syndrome. Intensive Care Med 42:1137-1145

7. Zinter MS, Spicer A, Orwoll BO, Alkhouli M, Dvorak CC, Calfee CS, Matthay MA, Sapru A (2016) Plasma angiopoietin-2 outperforms other markers of endothelial injury in prognosticating pediatric ARDS mortality. Am J Physiol Lung Cell Mol Physiol 310:L224-231

8. Calfee CS, Janz DR, Bernard GR, May AK, Kangelaris KN, Matthay MA, Ware LB (2015) Distinct molecular phenotypes of direct vs. indirect ARDS in single-center and multicenter studies. Chest 147:1539-1548

9. Mrozek S, Jabaudon M, Jaber S, Paugam-Burtz C, Lefrant JY, Rouby JJ, Asehnoune K, Allaouchiche B, Baldesi O, Leone M, Lu Q, Bazin JE, Roszyk L, Sapin V, Futier E, Pereira B, Constantin JM, Azurea Network (2016) Elevated plasma levels of sRAGE are associated with nonfocal CT-based lung imaging in patients with ARDS: a prospective multicenter study. Chest 150:998-1007

10. Jabaudon M, Hamroun N, Roszyk L, Guerin R, Bazin JE, Sapin V, Pereira B, Constantin JM (2015) Effects of a recruitment maneuver on plasma levels of soluble RAGE in patients with diffuse acute respiratory distress syndrome: a prospective randomized crossover study. Intensive Care Med 41:846-855

11. Jabaudon M, Futier E, Roszyk L, Sapin V, Pereira B, Constantin JM (2015) Association between intraoperative ventilator settings and plasma levels of soluble receptor for advanced glycation end-products in patients without pre-existing lung injury. Respirology 20:1131-1138

12. Guervilly C, Lacroix R, Forel JM, Roch A, Camoin-Jau L, Papazian L, DignatGeorge F (2011) High levels of circulating leukocyte microparticles are associated with better outcome in acute respiratory distress syndrome. Crit Care 15:R31 
13. Forel JM, Guervilly C, Hraiech S, Voillet F, Thomas G, Somma C, Secq V, Farnarier C, Payan MJ, Donati SY, Perrin G, Trousse D, Dizier S, Chiche L, Baumstarck K, Roch A, Papazian L (2015) Type III procollagen is a reliable marker of ARDS-associated lung fibroproliferation. Intensive Care Med 41:1-11

14. Calfee CS, Delucchi K, Parsons PE, Thompson BT, Ware LB, Matthay MA, Network NA (2014) Subphenotypes in acute respiratory distress syndrome: latent class analysis of data from two randomised controlled trials. Lancet Respir Med 2:611-620

15. Famous KR, Delucchi K, Ware LB, Kangelaris KN, Liu KD, Thompson BT, Calfee CS, Network A (2017) Acute respiratory distress syndrome subphenotypes respond differently to randomized fluid management strategy. Am J Respir Crit Care Med 195:331-338

16. Jabaudon M, Blondonnet R, Pereira B, Cartin-Ceba R, Lichtenstern C, Mauri T, Determann RM, Drabek T, Hubmayr RD, Gajic O, Uhle F, Coppadoro A, Pesenti A, Schultz MJ, Ranieri MV, Brodska H, Mrozek S, Sapin V, Matthay MA, Constantin JM, Calfee CS (2018) Plasma sRAGE is independently associated with increased mortality in ARDS: a meta-analysis of individual patient data. https://doi.org/10.1007/s00134-018-5327-1 